\title{
O ACORDO DE PARIS NA PERSPECTIVA DA INDEPENDÊNCIA ENERGÉTICA DE WASHINGTON
}

\author{
Flávio Marcelo Rodrigues Bruno ${ }^{1}$ \\ Raimundo Giovanni França Matos ${ }^{2}$
}

\begin{abstract}
Resumo: O presidente dos Estados Unidos anunciou a retirada do segundo maior poluidor do mundo, do Acordo de Paris sobre o combate as mudanças climáticas. O acordo foi assinado por 196 países com o intuito de reduzir o aquecimento global. A decisão provoca um terremoto político em todo o mundo e prejudica de forma intensa o combate às mudanças climáticas. É neste contexto que o presente trabalho pretende revisitar o Acordo sobre o combate ao aquecimento global após a Ordem Executiva de Independência Energética de Washington. Tendo como objetivo buscar compreender a dimensão da desregulamentação climática norteamericana.
\end{abstract}

Palavras-chave: Direito Internacional; Acordo de Paris; Clima; Aquecimento global.

\section{THE PARIS AGREEMENT IN THE PERSPECTIVE OF WASHINGTON'S ENERGY INDEPENDENCE}

\begin{abstract}
The president of the United States has announced the withdrawal of the second largest polluter in the world, the Paris Agreement on combating climate change. The agreement was signed by 196 countries with the aim of reducing global warming. The decision provokes a political earthquake around the world and harms intensely the fight against climate change. It is in this context that the present work intends to revisit the Agreement on the fight against
\end{abstract}

\footnotetext{
1 Doutorando em Direito (UERJ). Mestre em Direito (PUC-PR). Mestre em Economia (UNISINOS-RS). Especialista em Direito e Economia (UFRGS). Graduado em Direito (UNISINOS). Pesquisador vinculado ao Grupo de Pesquisas em Direito Internacional dos Investimentos (UERJ) e ao Grupo de Estudos em Novas Tecnologias e o impacto nos Direitos Humanos (UNIT-SE), membro do Núcleo de Estudos Avançados de Direito Internacional e Desenvolvimento (Neadi/PUC-PR) e do Núcleo de Estudos e Pesquisas em Direito Internacional (Nepedi-UERJ), Líder do Grupo de Pesquisas em Direito, Natureza e Desenvolvimento Sustentável (UFOB). Professor do Curso de Graduação em Direito e do Curso de Especialização em Gestão da Inovação Tecnológica e Social, Vice Coordenador do Curso de Graduação em Direito e Vice Diretor do Centro das Humanidades (CEHU) da Universidade Federal do Oeste da Bahia (UFOB).

Endereço Eletrônico: flavio.bruno@msn.com

${ }^{2}$ Doutorando em Direito Político e Econômico (MACKENZIE-SP). Mestre em Direito (PUC-PR). Especialista em Direito Processual Civil (JUSPODIVM-BA). Graduado em Direito (UNIT-SE) Professor Adjunto e Coordenador do Curso de Graduação em Direito da Universidade Tiradentes (UNIT-SE).

Endereço Eletrônico: rg.adv@hotmail.com
} 
global warming after the Executive Order of Independence Energy of Washington. The objective is to understand the dimension of North American climate deregulation.

Keywords: International right; Paris Agreement; Climate; Global warming.

\section{INTRODUÇÃO}

O presidente dos Estados Unidos anunciou, em junho de 2017, a retirada de seu país, o segundo maior poluidor do mundo, do Acordo de Paris sobre o combate as mudanças climáticas, firmado em 2015 por 196 países com o intuito de reduzir o aquecimento global. A decisão tem, num dos lemas do chefe de Estado norte americano, uma clara sinalização: “America First”, e deve provocar um terremoto político em todo o mundo e prejudicar de forma intensa o combate às mudanças climáticas.

No discurso em que justifica a saída dos Estados Unidos do referido Acordo, o chefe de Estado norte-americano argumenta que o não cumprimento das obrigações estabelecidas no documento objetivam defender os empregos dos cidadãos americanos e que o Fundo Verde do Clima da Organização das Nações Unidas (ONU) é somente "uma forma disfarçada de distribuir riquezas para outros países”. Argumenta, ainda, que os Estados Unidos podem voltar a integrar o Acordo de Paris, porém, somente após uma negociação que seja mais benéfica para o país.

O presidente dos Estados Unidos afirmou que o acordo oferece aos outros países uma vantagem injusta sobre a indústria americana e destrói os empregos americanos. E que então, a partir de agora, os Estados Unidos cessarão toda a implementação do Acordo de Paris não vinculativo e os encargos financeiros e econômicos draconianos que o acordo impõe ao nosso país.

Como um dos maiores poluidores da atualidade, e o maior se levada em conta à história, os Estados Unidos tinham um papel determinante no Acordo de Paris, seja como exemplo ou como potências capaz de convencer as demais nações a cumprirem o que foi acordado. A saída de Washington, assim, pode reduzir drasticamente a eficácia do acordo. É inegável que a questão climática é uma das mais complexas da atual sociedade, envolvendo múltiplas dimensões, como a científica, a econômica, a social, a política, a moral e a ética. É um sério problema global de escalas regionais. E mesmo que cessem as emissões de gases de efeito estufa na atmosfera, o aquecimento global e as mudanças climáticas continuarão a afetar as gerações 


\section{O ACORDO DE PARIS NA PERSPECTIVA DA INDEPENDÊNCIA ENERGÉTICA DE WASHINGTON}

futuras. Desta forma, a humanidade está "comprometida" com algum nível de mudança climática.

Apesar da crescente conscientização sobre as mudanças climáticas, as emissões de gases de efeito estufa continuam em um aumento elevado. É preciso reduzir as emissões e buscar estabilizar os níveis de gases com efeito de estufa na atmosfera- mitigação, bem como adaptarse às mudanças climáticas já em andamento - adaptação. O objetivo da mitigação é evitar interferências humanas significativas no sistema climático e estabilizar os níveis de gases de efeito estufa em um prazo suficiente para permitir aos ecossistemas se adaptarem naturalmente às mudanças climáticas, garantir que a produção de alimentos não seja ameaçada e permitir que o desenvolvimento econômico prosseguir de forma sustentável. A adaptação à vida em um clima em mudança envolve o ajuste ao clima futuro atual ou esperado. O objetivo é reduzir nossa vulnerabilidade aos efeitos nocivos das mudanças climáticas Também abrange aproveitar todas as possíveis oportunidades benéficas associadas às mudanças climáticas.

É diante deste contexto que o presente trabalho pretende revisitar o Acordo de Paris sobre o combate ao aquecimento global após a Ordem Executiva de Independência Energética de Washington. Como pano de fundo, buscar compreender a dimensão da desregulamentação climática norte-americana. Num primeiro momento, o estudo analisa o acordo global sobre as mudanças do clima adotado em Paris. Na sequência, observa a temática central das discussões nas alterações climáticas globais e os sinais vitais do planeta. E ao final, expõem a nova política americana sobre o clima a partir da Ordem Executiva de Independência Energética de Washington.

Esclarecendo que não é objetivo e tampouco poderia o ser, o esgotamento do tema, por sua importância no mundo atual, seu dinamismo e sua necessidade de ser constantemente pauta de negociações que façam evoluir e não retroceder a pauta de combate às causas de alteração climática, dentre elas, a mais severa de todas - o aquecimento global. Tendo como pano de fundo a tentativa de elucidas a perspectiva que, a partir da retira dos Estados Unidos, se tem sobre o verdadeiro cumprimento do documento multilateral mais importante do Século 21 sobre o meio ambiente, fruto de intensas negociações e que tem como principal agenda a redução do impacto do homem na natureza em prol da preservação do planeta.

\section{O acordo global sobre as mudanças do clima adotado em Paris}


A Conferência das Nações Unidas sobre o Meio Ambiente Humano, de 1972, ocorrida em Estocolmo, na Suécia, reuniu 113 países, todas as organizações internacionais existentes da época e cerca de 700 observadores de diversas organizações não governamentais, o que significou um interesse crescente da sociedade civil pela matéria. Para a maioria da doutrina, a Conferência de Estocolmo, constituiu no plano jurídico o verdadeiro ponto de partida para uma percepção global da preocupação com o meio ambiente, tanto na esfera da construção de normas internacionais como no desenvolvimento da doutrina sobre o tema (DINH et al, 2003). É tida como o primeiro tratado que apresentava princípios com objetivo de proteção do meio ambiente, entre eles o referente ao desenvolvimento sustentável.

A primeira reunião que apresentou em suas negociações, rodadas específicas sobre as alterações climáticas aconteceu em 1992 durante a Conferência das Nações Unidas sobre Meio Ambiente e Desenvolvimento no Rio de Janeiro (ECO-92), da qual resultou o texto da Convenção do Clima, assinado e ratificado por 175 países, reconhecendo a necessidade de um esforço global para o enfrentamento das questões climáticas. Com a entrada em vigor da referida Convenção, os representantes dos diferentes países passaram a se reunir anualmente para discutir a sua implementação, estas reuniões são chamadas de Conferências das Partes (COPs).

A Conferência das Nações Unidas sobre o Meio Ambiente e Desenvolvimento, de 1992 (ECO-92), contou com a presença de 178 delegações e também ficou conhecida como a Cúpula da Terra (RIO-92). Dois documentos anteriores foram significativos para as negociações da Conferência (ECO-92), um deles foi o Relatório Brundtland, de 1987 que conceituava desenvolvimento sustentável e foi a diretriz das resoluções de 1992, e o levantamento emitido pelo Painel Intergovernamental sobre Mudanças Climáticas (IPCC), de 1990, que afirmou pela primeira vez, com rigor científico, que a temperatura da Terra estava crescente em razão da emissão de gases de efeito estufa.

Na Conferência (ECO-92) foi criada a Convenção-Quadro das Nações Unidas sobre Mudança do Clima (UNFCCC), que deu origem a um regime de mudanças climáticas que está contido em um complexo de regimes com temática similar. Há uma causa transversal onde às partes atuam por integração ou por fragmentação. (KEOHANE e VICTOR, 2010). Haja vista ainda no contexto da Organização das Nações Unidas (ONU), se apresentam as agências especializadas como a Organização Mundial de Meteorologia (OMM), o Programa das Nações Unidas para o Desenvolvimento (PNUD), a Fundação para a Alimentação e Agricultura (FAO, 


\section{O ACORDO DE PARIS NA PERSPECTIVA DA INDEPENDÊNCIA ENERGÉTICA DE WASHINGTON}

sigla em inglês) e Agência Internacional para a Energia Atômica (IAEA, sigla em inglês). As questões de tema ambiental são por si só, complexas, por serem multidisciplinares, e sua operacionalização igualmente se apresenta de forma complexa.

Mesmo a Convenção-Quadro das Nações Unidas sobre Mudança do Clima (UNFCCC) esclarecendo a necessidade da redução de emissão de gases de efeito estufa, não se chegou a delimitar objetivos de forma direta e específica para efetivar ações de combate. A ConvençãoQuadro (UNFCCC) tem o objetivo de estabilizaras concentrações de gases de efeito estufa na atmosfera em um nível que impeça uma interferência antrópica perigosa no sistema climático. Esse nível deverá ser alcançado em um prazo suficiente que permita aos ecossistemas adaptarem-se naturalmente à mudança do clima, assegurando que a produção de alimentos não seja ameaçada e permitindo ao desenvolvimento econômico prosseguir de maneira sustentável. Para que se possibilite a operacionalização de uma agenda de redução foram criadas as Conferências das Partes (COPs), reuniões com estes objetivos específicos. (UNFCCC, 2017)

Reconhecida como um órgão supremo da Convenção-Quadro das Nações Unidas sobre Mudança do Clima (UNFCCC), reúne anualmente os países em conferências mundiais. Suas decisões, coletivas e consensuais, só podem ser tomadas se forem aceitas unanimemente pelas nações envolvidas, sendo soberanas e valendo para todos os países signatários da ConvençãoQuadro (UNFCCC). Seu objetivo é manter de forma regular o exame sobre as questões climáticas e tomar as decisões necessárias para promover a efetiva implementação dos objetivos de redução das alterações climática e de quaisquer instrumentos jurídicos que a Conferência das Partes (COP) possa adotar. (UNFCCC, 2017)

Também compete ao órgão: examinar periodicamente as obrigações dos países e os mecanismos institucionais estabelecidos pela Convenção-Quadro (UNFCCC); - promover e facilitar o intercâmbio de informações sobre medidas adotadas pelos países para enfrentar a mudança do clima e seus efeitos; promover e orientar o desenvolvimento e aperfeiçoamento periódico de metodologias comparáveis, a serem definidas pela Conferência das Partes (COP) para elaborar inventários de emissões de gases de efeito estufa por fontes e de remoções por sumidouros; e examinar e adotar relatórios periódicos sobre a implementação da ConvençãoQuadro (UNFCCC) que conta com um Secretariado, sediado em Bonn, na Alemanha, e que mantém atualizadas todas as informações relativas ao combate das alterações climática. (UNFCCC, 2017) 
No âmbito da Conferência das Partes (COP), um dos mais fundamentais princípios que se instaurou é o das responsabilidades comuns, porém diferenciadas, no sentido de que as partes devem proteger o sistema climático em benefício das gerações presentes e futuras com base na equidade e em conformidade com suas respectivas capacidades. Em decorrência disso, os países desenvolvidos que participam da Convenção-Quadro das Nações Unidas sobre Mudança do Clima (UNFCCC) devem tomar a iniciativa no combate à mudança do clima e seus efeitos, devendo considerar as necessidades específicas dos países em desenvolvimento, em especial os particularmente vulneráveis aos efeitos negativos da mudança do clima. Convém destacar que o Brasil foi o primeiro país a assinar a Convenção-Quadro (UNFCCC), que somente começou a vigorar em 29 de maio de 1994, 90 dias depois de ter sido aprovada e ratificada pelo Congresso Nacional.

Da $3^{a}$ Conferência das Partes (COP) surgiu, em 1997, o Protocolo de Kyoto com metas obrigatórias para os países desenvolvidos reduzirem 5\% das emissões de gases de efeito estufa. O Protocolo de Kyoto constitui um tratado complementar à Convenção-Quadro das Nações Unidas sobre Mudança do Clima (UNFCCC), definindo metas de redução de emissões para os países desenvolvidos e os que, à época, apresentavam economia em transição para o capitalismo, considerados os responsáveis históricos pela mudança atual do clima. Entrou em vigor no dia 16 de fevereiro de 2005, logo após o atendimento às condições que exigiam a ratificação por, no mínimo, 55\% do total de países-membros da Convenção-Quadro (UNFCCC) e que fossem responsáveis por, pelo menos, 55\% do total das emissões de 1990.

Durante o primeiro período de compromisso, entre 2008 a 2012, 37 países industrializados e a Comunidade Europeia (CE) comprometeram-se a reduzir as emissões de gases de efeito de efeito estufa para uma média de 5\% em relação aos níveis de 1990. No segundo período de compromisso, as países signatários se comprometeram a reduzir as emissões em pelo menos 18\% abaixo dos níveis de 1990 no período de oito anos, entre 2013 e 2020.

Cada país negociou a sua própria meta de redução de emissões em função da sua visão sobre a capacidade de atingi-la no período considerado. Entre os principais emissores de gases de efeito estufa, somente os Estados Unidos não ratificaram o Protocolo de Kyoto. No entanto, continuaram com responsabilidades e obrigações definidas pela Convenção-Quadro das Nações Unidas sobre Mudança do Clima (UNFCCC). 


\section{O ACORDO DE PARIS NA PERSPECTIVA DA INDEPENDÊNCIA ENERGÉTICA DE WASHINGTON}

Foi adotado por consenso em dezembro de 2015, em Paris, um novo acordo global que busca combater os efeitos das mudanças climáticas, bem como reduzir as emissões de gases de efeito estufa. Em novembro de 2016, entra em vigor o documento, então chamado de Acordo de Paris, que foi ratificado pela União Europeia, pela Autoridade Palestina e mais 195 países signatários da Convenção-Quadro das Nações Unidas sobre Mudança do Clima (UNFCCC), durante a $21^{a}$ Conferência das Partes (COP-21). Um dos objetivos ${ }^{3}$ é manter o aquecimento global “muito abaixo de $2^{\circ} \mathrm{C}$ ”, buscando ainda “esforços para limitar o aumento da temperatura a $1,5^{\circ} \mathrm{C}$ acima dos níveis pré-industriais”. Este foi o mais recente esforço multilateral para a construção sólida de uma arquitetura de regulação internacional no contexto das mudanças climáticas. Os países signatários comprometeram-se a elaborar uma estratégia global "para proteger o sistema climático para gerações presentes e futuras”. (UNFCCC, 2015)

Além disso, o documento busca incrementar a capacidade dos países de se adaptarem às mudanças climáticas, sempre levando em consideração a “segurança alimentar”. Por último, defende conseguir com que os "fluxos financeiros” caminhem para uma economia baixa em emissões de gases de efeito estufa. Com o estabelecimento claro das metas, para atingir o objetivo de manter o aumento da temperatura média no fim do século entre $1,5^{\circ} \mathrm{C}$ e $2^{\circ} \mathrm{C}$, o Acordo de Paris estabelece que todos os países devem alcançar um teto em suas emissões de gases de efeito estufa “o quanto antes”.

Os países desenvolvidos deverão fazer isso primeiro. As nações em desenvolvimento terão mais tempo, ainda que não esteja estipulado um prazo concreto. Outro aspecto abordado é que, até a segunda metade deste século, é preciso chegar a um equilíbrio entre as emissões e a capacidade de absorver esses gases, principalmente o dióxido de carbono $\left(\mathrm{CO}_{2}\right)$. Esse último ponto abre a porta de maneira clara aos mecanismos de sequestro e armazenamento de carbono, um caminho defendido pelos países produtores de petróleo para que não se corte imediatamente os combustíveis fósseis. (UNFCCC, 2015)

A mitigação é outra meta do Acordo de Paris. A grande maioria dos países presentes a $21^{a}$ Conferencia das Partes (CPO-21) já apresentaram planos de redução de suas emissões de

\footnotetext{
${ }^{3}$ De acordo com o artigo $2^{\circ}$ da Convenção de Paris, os objetivos principais do Tratado são: (a)manter o aumento da temperatura média global bem abaixo de $2^{\circ} \mathrm{C}$ em relação aos níveis pré- industriais, e envidar esforços para limitar esse aumento da temperatura a $1,5^{\circ} \mathrm{C}$ em relação aos níveis pré-industriais, reconhecendo que isso reduziria significativamente os riscos e os impactos da mudança do clima; (b) Aumentar a capacidade de adaptação aos impactos negativos da mudança do clima e promover a resiliência à mudança do clima e um desenvolvimento de baixa emissão de gases de efeito estufa, de uma maneira que não ameace a produção de alimentos; e (c) Tornar os fluxos financeiros compatíveis com uma trajetória rumo a um desenvolvimento de baixa emissão de gases de efeito estufa e resiliente à mudança do clima. (UNFCCC, 2015).
} 
gases de efeito estufa. Quando analisados em conjunto, esses programas de redução de emissões resultam em um aumento de cerca de $3^{\circ} \mathrm{C}$ na temperatura até o fim do Século 21. Por isso, o Acordo estabelece que as contribuições devem ser revisadas para cima a cada cinco anos. A primeira análise será realizada em 2018, e a segunda atualização, em 2020, quando entrará em vigor o Acordo de Paris. Exige-se que os países desenvolvidos reduzam suas emissões em suas contribuições nacionais. As nações em desenvolvimento estão sendo incentivadas a limitar suas emissões ou reduzi-las de acordo com suas capacidades. (UNFCCC, 2015)

Um dos instrumentos fundamentais do acordo é a criação de inventários para que se possa fazer um bom acompanhamento dos programas nacionais de redução. Estão estabelecidas três categorias em termos de países para acompanhar este ponto do documento: os países desenvolvidos, que deverão oferecer informações completas, os países emergentes, que terão uma exigência menor, e os países mais pobres, que terão um nível mínimo de obrigações. (UNFCCC, 2015)

O Acordo de Paris será vinculante. O que não será legalmente vinculante são os objetivos de redução de emissões de cada um dos países. (UNFCCC, 2015). Esse ponto teve que ser incluído para evitar que os Estados Unidos, o segundo maior emissor do mundo, não ficasse fora do pacto já que o país teria problemas para ratificá-lo em casa se fossem impostas, de fora, metas concretas de redução das emissões - o que se demonstrou ineficaz após o anúncio de retirada de Washington da esfera de aplicação do Acordo.

Para que os países com menos recursos possam se adaptar aos efeitos das mudanças climáticas e para que também possam reduzir suas emissões de gases de efeito estufa na atmosfera, está estabelecida a obrigação de que exista uma ajuda internacional. Os países desenvolvidos são os que devem mobilizar os fundos. Outras nações também poderiam fazer aportes, mas de maneira “voluntária”. O compromisso é conseguir que, até 2025, sejam levantados US\$ 100 bilhões anuais, apesar de ainda não estar fixada uma data para a revisão antes daquele ano. (UNFCCC, 2015)

Além disso, o documento inclui a criação de um organismo internacional novo dedicado às "perdas e danos”. Ou seja, para compensar os países que serão mais atingidos pelas consequências das mudanças climáticas. O desenvolvimento desse novo órgão ficará para o futuro. Por último, o acordo inclui ainda a criação de mecanismos de mercado de emissões de gases de efeito estufa. (UNFCCC, 2015) 


\section{O ACORDO DE PARIS NA PERSPECTIVA DA INDEPENDÊNCIA ENERGÉTICA DE WASHINGTON}

Convenção-Quadro das Nações Unidas sobre Mudança do Clima (UNFCCC) é uma Convenção universal de princípios, reconhecendo a existência de mudanças climáticas antropogênicas - ou seja, de origem humana - e dando os países industrializados a maior parte da responsabilidade para combatê-la. A $21^{a}$ Conferencia das Partes (CPO-21) buscava alcançar um novo acordo internacional sobre o clima, aplicável a todos os países, com o objetivo de manter o aquecimento global abaixo dos $2^{\circ} \mathrm{C}$. O Acordo de Paris marca um momento decisivo de transformação para reduzir os riscos da mudança climática. Pela primeira vez, cada país do mundo se compromete a reduzir as emissões, fortalecer a resiliência e se unir em uma causa comum para combater a mudança do clima. O que já foi impensável se tornou um caminho sem volta.

A Organização das Nações Unidas (ONU) vislumbra o progresso na erradicação da pobreza, no fortalecimento da paz e na garantia de uma vida de dignidade e oportunidade para todos, e do ponto de vista da arquitetura jurídica internacional sobre as questões climáticas, o Acordo de Paris reflete o avanço em todas as áreas possível de combate ao aquecimento global, a promoção e a preservação do meio ambiente e seu desenvolvimento sustentável sob o viés de ações globais.

\section{As alterações climáticas globais e os sinais vitais do planeta.}

De acordo com os estudos de Foucault (2015), clima é o comportamento dinâmico das condições da atmosfera em determinado local, é composto por um conjunto de variáveis meteorológicas sucessivas e que ciclicamente se repetem ao longo temporal de meses ou anos. Quando se aborda o clima, é feita referência a um conjunto de dados que envolvem a temperatura, a intervenção da luz solar, o grau de precipitações, a umidade do ar e a pressão atmosférica. $^{4}$

A dinâmica do clima sofre influências humanas em todas as suas composições, o que ocasiona a determinação das mudanças climáticas. ${ }^{5}$ A influência da ação humana sobre o clima

\footnotetext{
${ }^{4}$ O Painel Intergovernamental sobre Mudanças Climáticas (IPCC, sigla em inglês), uma organização científicopolítica no âmbito do Programa das Nações Unidas para o Meio Ambiente (PNUMA) e da Organização Meteorológica Mundial (OMM), conceitua o clima em sentido estrito como 'tempo meteorológico médio', ou mais precisamente, como a descrição estatística de quantidades relevantes de mudanças do tempo meteorológico num período de tempo, que vai de meses a milhões de anos. O período clássico é de 30 anos, definido pela Organização Mundial de Meteorologia (OMM). Essas quantidades são geralmente variações de superfície como temperatura, precipitação e vento. O clima num sentido mais amplo é o estado, incluindo as descrições estatísticas do sistema global. (IPCC, 2014).

${ }^{5}$ Em sua definição, a mudança climática é uma variação estatisticamente significante em um parâmetro climático médio (incluindo sua variabilidade natural), que persiste num período extenso (tipicamente décadas ou por mais
} 
é clara e indiscutível. Nesse sentido, em fundamental relatório, o Painel Intergovernamental sobre Mudanças Climáticas (IPCC, sigla em inglês), determinou que as emissões de gases de efeito estufa ${ }^{6}$ produzidas pelas atividades humanas, como a queima de combustíveis fósseis (derivados do petróleo, carvão mineral e gás natural) para geração de energia, as atividades industriais e de transportes; a conversão do uso do solo; a agropecuária; o descarte de resíduos sólidos (lixo) e o desmatamento são os principais fatores negativos dessa interferência humana no clima, e têm crescido sem cessar, estando atualmente nos níveis mais altos já verificados na história. (IPCC, 2014; NOAA, 2017).

Os efeitos negativos das emissões de gases de efeito estufa levam ao aquecimento global, inequivocamente o mais contundente efeito sobre a sociedade humana, e muitas das mudanças observadas nas últimas décadas não têm precedentes. O aquecimento global é um fenômeno climático de extensão significativa. Ensinam Silva e Paula (2009) que os fatores de interferência humana são tidos como antropogênicos e são relacionados à emissão de gases de efeito estufa e grande parte do aumento de concentração desses gases é a causadora do aquecimento global.

A temperatura média na superfície terrestre e oceânica no ano de 2016 foi a mais alta desde 1880, é o terceiro ano consecutivo de recordes do aquecimento global. De acordo com a Administração Nacional para os Oceanos e a Atmosfera (NOAA, sigla em inglês,), em seu relatório anual sobre o clima global, "durante 2016, a temperatura média na terra e nos oceanos esteve 0,94 graus Celsius $\left({ }^{\circ} \mathrm{C}\right.$ ) acima da média do Século 20 que foi de $13,9^{\circ} \mathrm{C}$ e registrando o nível mais alto desde 1880”. O relatório ainda acrescenta que desde o início do Século 21 o recorde de temperatura global anual aumentou cinco vezes nos ano de 2005, 2010, 2014, 2015 e 2016. (NOAA, 2017, p.6).

O infográfico na sequência demonstra de forma didática como é possível identificar o aumento da temperatura em diferentes níveis ao longo de um determinado período de análise

tempo). Em termos abstratos, a mudança climática pode ser causada por processos naturais, e realmente no passado da Terra houve variações importantes no clima, como por exemplo, os períodos glaciais. Contudo, a mudança recente tem sua causa nas atividades humanas. (IPCC, 2014).

${ }^{6}$ A atmosfera, a camada de ar que envolve o planeta Terra, é constituída por vários gases. Os principais são o nitrogênio $\left(N_{2}\right)$ e o oxigênio $\left(\mathrm{O}_{2}\right)$ que, juntos, compõem cerca de $98,9 \%$ da atmosfera. Vários outros gases encontram-se presentes em pequenas quantidades e, naturalmente, constituem os conhecidos "gases de efeito estufa” como o dióxido de carbono $\left(\mathrm{CO}_{2}\right)$, ozônio $\left(\mathrm{O}_{3}\right)$, metano $\left(\mathrm{CH}_{4}\right)$ e o óxido nitroso $\left(\mathrm{N}_{2} \mathrm{O}\right)$, hidrofluorcarbonos (HFCs), perfluorcarbonos (PFCs), hexafluoreto de enxofre ( $\left.\mathrm{SF}_{6}\right)$, juntamente com o vapor d'água $\left(\mathrm{H}_{2} \mathrm{O}\right)$. O mais poluente entre eles é o dióxido de carbono (CO2), cuja concentração na atmosfera saltou de 288 partes por milhão (ppm) no período pré-industrial (até 1750) para 378,9ppm em 2005, e que em números atuais de 2017 já está em 406,17ppm. (BRASIL, 1999; ALVES, 2017). 


\section{O ACORDO DE PARIS NA PERSPECTIVA DA INDEPENDÊNCIA ENERGÉTICA DE WASHINGTON}

do clima. De autoria de Hawkings ${ }^{7}$, o desenho demonstra o processo de uma forma um pouco diferente, se utilizando de círculos para mostrar que estamos vivendo em um mundo cada vez mais quente. Para produzir o gráfico, foram utilizados dados que registram o clima desde janeiro de 1850 e seguem até março de 2017. Ele os organizou de forma que, quanto mais quente era a temperatura, mais próxima ela ficava das bordas.
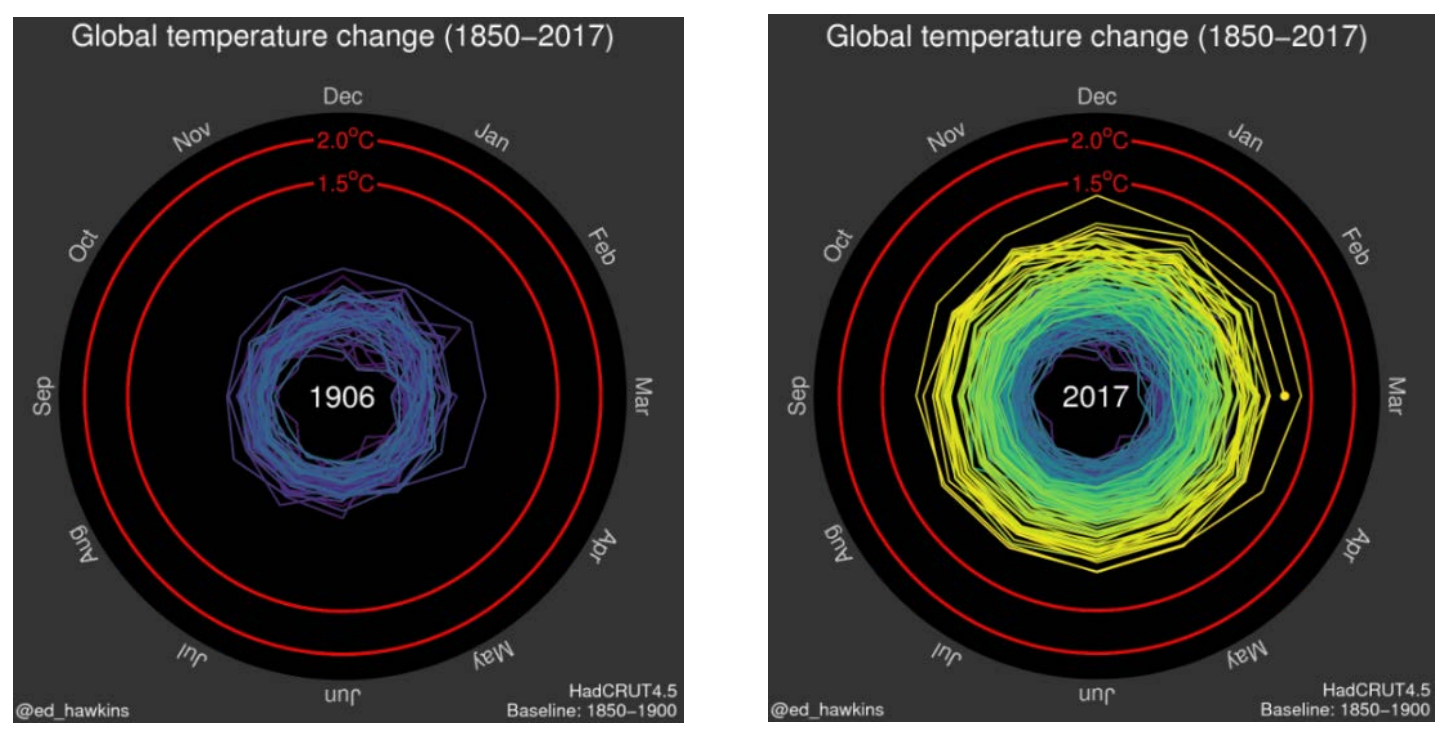

Infográfico: espiral global de demonstração da temperatura, entre 1850-2016.

Fonte: Climate Lab Book. Acessível em: http://www.climate-lab-ook.ac.uk/spirals/.

Os $2^{\circ} \mathrm{C}$ localizados nas extremidades do gráfico são uma comparação com a temperatura do período pré-industrial e não foram escolhidos ao acaso. É o máximo de elevação que os termômetros terrestres devem atingir depois que nações do mundo inteiro prometeram unir forças para segurar as mudanças climáticas, ao assinar o Acordo de Paris de 2015. Elevação suficiente para desestabilizar o funcionamento do planeta.

Em demonstração infográfica da sequência, da Administração Nacional da Aeronáutica e do Espaço (NASA, sigla em inglês), é possível comparar os níveis das camadas de gelo global com a extensão de gelo oceânico nos polos de 2000 a 2016, demonstrando que continuam em séria regressão. No Ártico, no inverno de 2016, foi registada a menor extensão pelo segundo ano consecutivo, enquanto na época do degelo foi registada a menor área desde que existem se iniciaram as séries de registros, com uma regressão do gelo semelhante à ocorrida em 2007. Na Antártida, no inverno, a extensão do manto de gelo oceânico foi a décima mais baixa e no degelo foi registado o nono mínimo em termos de área coberta de gelo. Quanto aos oceanos, a

\footnotetext{
${ }^{7}$ Climate Lab Book. Acessível em: http://www.climate-lab-ook.ac.uk/spirals/.
} 
temperatura ficou $0,75^{\circ} \mathrm{C}$ acima da média do século passado, ligeiramente superior ao anterior pico, atingido em 2015. O último mês do ano de 2016 foi considerado o terceiro dezembro mais quente desde 1880. (NOAA, 2017).
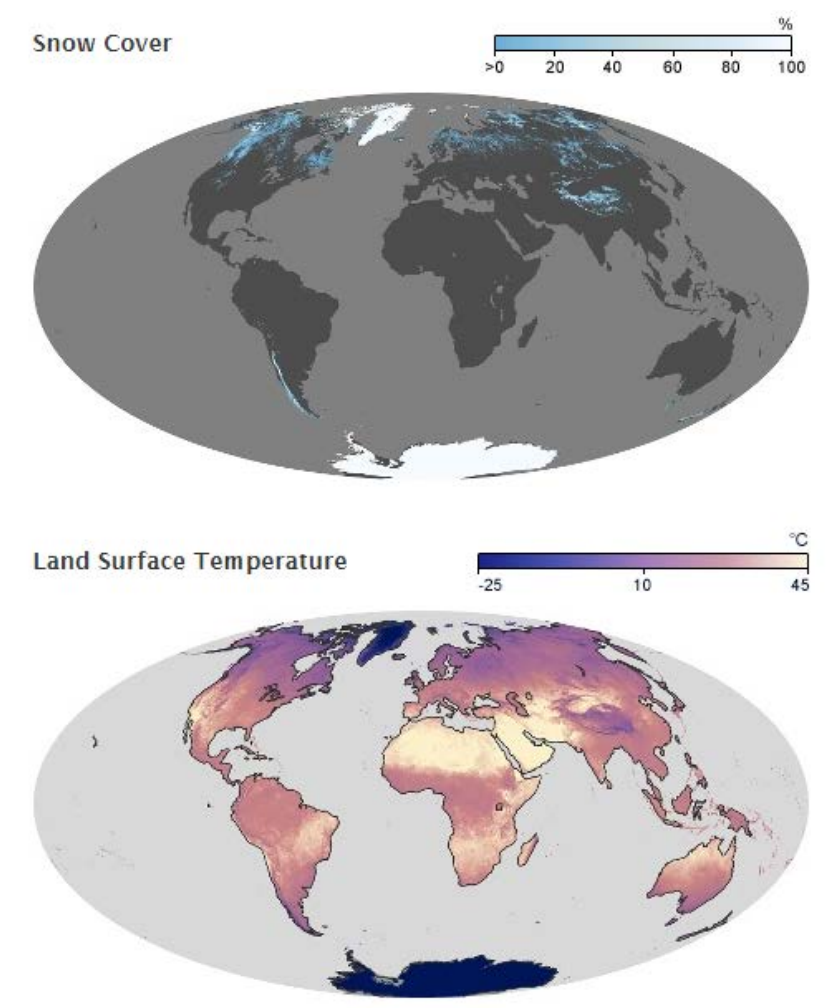

Infográfico: comparativo do nível de gelo global em relação aos níveis de temperatura terrestre em setembro de 2016.

Fonte: National Aeronautics and Space Administration. Acessível em: https://www.nasa.gov/.

De acordo com as principais agencias que registram o clima na Terra, as evidências científicas do aquecimento global são irrefutáveis. (IPCC; NOAA; OMM). Os levantamentos mais relevantes e contundes são os realizados pela Administração Nacional da Aeronáutica e do Espaço (NASA), disponíveis em seu website para ampla divulgação e consulta. E de acordo com estes levantamentos, é possível identificar as evidências e as causas das mudanças climáticas. Se também considerar-se, além do órgão, as demonstrações e revisões de literatura, será possível determinar que as mudanças climáticas sejam relevantes e irrefutáveis cientificamente, ainda mais se forem consideradas em suas evidências.

Constata-se um aumento do nível do mar: os estudos indicam que o nível global do mar subiu o dobro do século passado (CHURCH e WHITE, 2006; NASA, 2017). É inegável o aumento global da temperatura: a temperatura média da superfície aumentou de forma 


\section{O ACORDO DE PARIS NA PERSPECTIVA DA INDEPENDÊNCIA ENERGÉTICA DE WASHINGTON}

significativa, impulsionada, principalmente, pelo aumento dos gases estufa. A maior parte do aquecimento global ocorreu nos últimos 35 anos, não apenas o ano de 2016 foi o mais caloroso já registrado, como oito de seus doze anos foram os mais quentes em comparação com outros meses de anos anteriores. (NASA, 2017). Dados demonstram o aquecimento dos oceanos: os oceanos absorveram parte significativa desse aumento do calor (LEVITUS et al, 2009; NASA, 2017). Houve redução das camadas de gelo: o gelo na Groenlândia diminuiu em massa, perdendo de 150 a $250 \mathrm{~km}^{3}$ de gelo no período de 2002 a 2006, enquanto a Antártida perdeu cerca de $152 \mathrm{~km}^{3}$ entre 2002 e 2005. (CHEN et al, 2006; DOWDESWELL, 2006; NASA, 2017). Registrou-se um declínio do gelo do mar Ártico: tanto as extensões como a espessura do gelo do mar Ártico diminuíram rapidamente nas últimas décadas. (POLYAK et al, 2009; KWOK e ROTHROCK, 2009; NASA, 2017). Houve uma retração glacial: as geleiras estão recuando em todo o mundo, incluindo os Alpes, o Himalaia, os Andes, as Montanhas Rochosas, o Alaska e a África. (NSIDC, 2017; NASA, 2017). Registraram-se eventos naturais extremos: o número de eventos naturais como chuvas torrenciais, tempestades com tornados, ciclones e tsunamis, ventanias, ondas de calor e frio intensas, nevascas, secas e inundações tem aumentado tanto em altas temperaturas como em baixas desde 1950. (NASEM, 2016; NASA, 2017). Ocorreu um aumento da acidez oceânica: desde a Revolução Industrial, a acidez das águas aumentou em cerca de 30\%. Esse aumento é o resultado da ação humana emitindo gases estufa na atmosfera, aumentando a absorção por parte dos oceanos em sua camada mais superior. (SABINE et al, 2004; TCD, 2009; PMAL, 2017; NASA, 2017). Uma diminuição da cobertura de neve na primavera norte: as observações por satélite revelam que a quantidade de cobertura de neve da primavera no Hemisfério Norte diminuiu nas últimas cinco décadas e que a neve está derretendo mais cedo. (DERKSEN e BROWN, 2012; NSIDC, 2017; NASA, 2017).

A interferência humana é a principal causa das alterações climática. Mesmo que não se possa desconsiderar que nos levantamentos da Administração Nacional da Aeronáutica e do Espaço (NASA), aponte-se que as mudanças climáticas são uma constante na história geológica da Terra. Desde sua origem, há aproximadamente 4,55 bilhões de anos, o planeta Terra está em constante desenvolvimento, tendo passado por inúmeras alterações climáticas. Algumas dessas mudanças foram tão drásticas que diversos organismos vivos não foram capazes de se adaptar e foram extintos, como mostram os abundantes registros fósseis. (NASA, 2017). Nesse processo de desenvolvimento natural existem ciclos de aquecimento global devido à atuação combinada 
dos fatores internos: as massas continentais, por exemplo, em função do tectonismo de placas, estão em constante movimento, e as mudanças de latitude e longitude afetam o clima.

Modelos matemáticos climáticos projetam que as temperaturas globais de superfície provavelmente aumentarão no intervalo entre 1,1 e $6,4^{\circ} \mathrm{C}$, e o nível médio dos oceanos entre 9 a 88 cm entre 1990 e 2100. Os impactos não são apenas ambientais, mas econômicos e sociais. (PETIT et al. 1999, CHEN et al. 2006, DOWDESWELL, 2006). A generalidade dos estudos científicos considera que se a temperatura global aumentar para valores mais de $2^{\circ} \mathrm{C}$ acima dos existentes antes da Revolução Industrial provocará alterações climáticas severas e irreversíveis. Como se viu, grande parte da comunidade científica acredita que o aumento da concentração de poluentes antropogênicos na atmosfera é a causa principal do efeito estufa, consequentemente do aquecimento global. Mas as mudanças climáticas podem ter causas naturais como alterações na radiação solar e dos movimentos orbitais da Terra ou podem ser consequência das atividades humanas. O Painel Intergovernamental de Mudanças Climáticas (IPCC), órgão das Nações Unidas, responsável por produzir informações científicas, afirma que há 90\% de certeza que o aumento de temperatura na Terra está sendo causado pela ação do homem. (IPCC, 2014)

Assim, as atividades humanas passaram a ter influência importante nas mudanças climáticas. Historicamente, os países desenvolvidos tem sido responsáveis pela maior parte das emissões de gases de efeito estufa, mas os países em desenvolvimento vêm aumentando consideravelmente suas emissões. Dados do Instituto de Recursos Mundiais (WRI) ${ }^{8}$ identificam que atualmente, a China ocupa o primeiro lugar entre os maiores emissores de gases de efeito estufa na atmosfera, seguida por Estados Unidos, União Europeia e pelo Brasil.

Mesmo diante deste cenário, em junho de 2017, o governo norte-americano anunciou que sua retirada do Acordo de Paris, alegando que ele seria desvantajoso para as políticas de crescimento econômico, contrário aos interesses dos trabalhadores e injusto com a economia dos Estados Unidos. O texto prevê a possibilidade de retirada, mas a notificação só pode ser dada três anos após a entrada em vigor do Acordo de Paris, com a saída se efetuando um ano mais tarde.

Após a retirada dos Estados Unidos, o segundo maior emissor global de gases do efeito estufa, a China e a União Europeia se comprometeram a dar continuidade aos compromissos firmados em Paris. E mesmo em meio ao ato norte-americano, que sobremaneira enfraquece os

\footnotetext{
${ }^{8}$ World Resources Institute. Acessível em: http://www.wri.org
} 


\section{O ACORDO DE PARIS NA PERSPECTIVA DA INDEPENDÊNCIA ENERGÉTICA DE WASHINGTON}

objetivos traçados pelo Acordo de Paris sobre a redução do aquecimento global, os principais líderes mundiais assumiram o compromisso que os respetivos países vão intensificar os esforços para ajudar os países em desenvolvimento e, em particular os mais pobres e os mais ameaçados, para que alcancem os seus objetivos em matéria de aquecimento global, dando efetiva continuidade de uma política climática que preserve o planeta Terra.

\section{A Ordem Executiva de Independência Energética de Washington.}

Sem os Estados Unidos, que são o segundo maior produtor de gases de efeito estufa, o Acordo de Paris perde grande parte de seu sentido político e prático. Os cientistas da Climate Interactive realizaram uma simulação digital sobre o que ocorreria se todos os 194 países do mundo que assinaram o Acordo de Paris chegassem aos objetivos previstos pelo documento sobre a redução das emissões de $\mathrm{CO}_{2}$ até 2030, e considerando que as emissões de dióxido de carbono (CO2) na esfera do Acordo de Paris, e sem a vigência do Acordo. O resultado foi no sentido de que seriam despejados na atmosfera terrestre mais de 3 bilhões de toneladas de dióxido de carbono a mais a cada ano, com um aumento das temperaturas até o final do Século que ainda não pode ser calculado com margem razoável de certeza.

A chamada Ordem Executiva de Independência Energética tem como objetivo eliminar o Plano de Ação Climática, que previa a redução das emissões de gases do efeito estufa provenientes do carvão. A decisão coloca em risco o cumprimento dos compromissos norteamericanos perante o Acordo de Paris. Cabendo agora à Agência de Proteção Ambiental (EPA, sigla em inglês) redigir novas regras para as usinas energéticas alimentadas por energias fósseis, como o carvão. Os limites atuais haviam sido estabelecidos em níveis de redução de emissões em 30\% até 2030 com relação aos níveis de 2005. Apesar de ser uma das decisões de maior impacto, sua entrada em vigor não será imediata. Porém, os Estados Unidos sinalizam agora para o mundo que não dedicam mais a devida atenção para aquecimento global. (LEOPOLDO, 2017).

A Ordem Executiva também determinará uma revisão do Plano de Energias Limpas, uma diretriz que impunha restrições específicas às usinas energéticas e que motivou uma forte rejeição no Partido Republicano. "Pode-se responder à mudança climática sem prejudicar a economia, graças ao carvão limpo, à energia nuclear e inclusive às renováveis”. Washington parece sensível ao que denominou "guerra ao carvão” e “desvalorização dos trabalhadores” 
com suas políticas os dois Planos. O Presidente norte-americano considera que grande parte dessa regulamentação não ajudou a indústria. Os limites às emissões de poluentes impedem a geração de empregos e prejudicam a economia. O objetivo Ordem Executiva é recuperar a “independência energética” do país e “não aplicar políticas que ponham a economia em perigo”. (PEREDA, 2017).

A nova ordem executiva inclui a eliminação de várias moratórias impostas pelo governo americano anterior, bem como a abertura de um período de estudos para determinar se as restrições à poluição são de fato necessárias. A diretriz também indica que as agências governamentais não serão mais obrigadas a considerar as consequências ambientais das suas regulamentações, suspende a moratória nas autorizações para a exploração de carvão em terrenos federais, promove a exploração de gás e petróleo em território federal e elimina os limites à controvertida técnica do fracking. (PEREDA, 2017)

Washington afirmou que não há uma obrigação de regular as emissões de usinas poluentes e que sua missão prioritária é o crescimento econômico. Com as novas políticas da Ordem Executiva as políticas vigentes devem ser "revisadas, melhoradas e atualizadas de acordo com as prioridades do presidente”. Várias agências governamentais se encarregarão de estudar o plano de restrições às usinas energéticas, e suas conclusões, servirão de base para as futuras políticas ambientais. (PEREDA, 2017)

O decreto também elimina uma dezena de diretrizes para combater o aquecimento global nos Estados Unidos. Uma delas requeria um estudo de impacto de carbono para conceder licenças ambientais para empresas. (FLECK, 2017).

Além da Ordem Executiva de Independência Energética, especialistas indicam que outras ações de política estratégica tomadas por Washington são completamente contrárias ao caminho global de redução das mudanças climáticas causadas pela ação humana: alvos de constantes protestos de ambientalistas e populações nativas, dois oleodutos se preparam para operar o Keystone XL e o Dakota Access — que deverá passar por terras sagradas para os povos tradicionais e por reservas hídricas importantes, como o Rio Missouri. As orientações de revisão da condição de dezenas de monumentos nacionais de forma a possibilitar um melhor acesso para a perfuração de petróleo e gás. Uma moratória sobre a mineração de carvão em terras federais foi suspensa, enquanto o orçamento federal prevê perfurações em um refúgio natural no Alasca. Na proposta orçamentária Agência de Proteção Ambiental (EPA) teria destinação de verba 31\% menor em relação a 2016. Funcionários da agência e parlamentares — inclusive 


\section{O ACORDO DE PARIS NA PERSPECTIVA DA INDEPENDÊNCIA ENERGÉTICA DE WASHINGTON}

republicanos — denunciam que a medida poderia levar um colapso no programa ambiental do governo e na própria proteção aos recursos naturais no país. (BATISTA, 2017; LEOPOLDO, 2017; GIRARDI, 2017).

Nos Estados Unidos, mesmo que governo atual sinalize dar um novo impulso às fontes fósseis de energia, o que ele não poderá ignorar é que o setor de energias renováveis cria mais empregos, não só em relação à média da economia americana, mas em relação a toda a indústria de combustíveis fósseis: o setor de energia solar, em 2016, criou mais empregos do que os setores de carvão, petróleo e gás natural no seu conjunto. Isso significa que há benefícios econômicos associados à ação climática e geração de empregos. Não se poderá ignorar isso e reverter uma tendência que já ocorre e que não depende única e exclusivamente do governo federal dos Estados Unidos. (BATISTA, 2017; LEOPOLDO, 2017; GIRARDI, 2017).

Estados americanos estão empenhados no desenvolvimento de políticas de promoção de fontes de energia renováveis, municípios americanos também, e a maioria da população americana apoia a ação climática e os investimentos em energias renováveis. Então, se o mundo terá que se adaptar a nova geopolítica americana na agenda de clima e em vários outros temas, Washington também terá que se adequar à realidade, que é indiscutível, da transição energética e à realidade de quão competitivas são as fontes de energia renováveis.

\section{CONSIDERAÇÕES FINAIS}

De acordo com o Instituto de Recursos Mundiais (WRI) a China ocupa o primeiro lugar entre os maiores emissores de gases de efeito estufa na atmosfera, sendo seguida por Estados Unidos, União Europeia e pelo Brasil. Estas nações representam os maiores emissores de gases nocivos ao meio ambiente, refletindo mais de dois terços do total global de emissões.

Mesmo diante deste cenário, em junho de 2017, o governo norte-americano anunciou a sua retirada do Acordo de Paris que foi ratificado pela União Europeia, pela Autoridade Palestina e por mais 195 nações que fazem parte da Convenção-Quadro das Nações Unidas sobre Mudança do Clima (UNFCCC, sigla em inglês), durante a $21^{a}$ Conferência das Partes (COP-21), ocorrida em Paris, em 2015. O governo americano alegou que o Acordo de Paris seria desvantajoso para as políticas de crescimento econômico, contrário aos interesses dos trabalhadores e injusto com a economia dos Estados Unidos. 
Com o anúncio de Washington, o país se torna membro do seleto clube de nações que não assumiram um compromisso internacional comum na luta contra as mudanças climáticas. Um conglomerado composto por apenas três membros: Síria, Nicarágua e, agora, os Estados Unidos. O restante dos países do mundo, incluindo nações como Coréia do Norte e a Somália assinaram o Acordo de Paris que prevê até 2030 a limitação do aumento das temperaturas mundiais em um nível mais próximo possível de $1,5^{\circ}$ graus Celsius $\left({ }^{\circ} \mathrm{C}\right)$ em relação aos níveis pré-industriais. Inclusive os países membros da Organização dos Países Exportadores de Petróleo (OPEP), maiores interessados em preservar o uso global dos combustíveis fósseis, assinaram o documento.

A decisão de Washington abalou as estruturas de um movimento global em prol da defesa do meio ambiente, da cooperação pelo clima, das alterações climáticas e da diminuição dos impactos ambientais causados pela emissão de gases de efeito estufa na atmosfera. Um retrocesso nas políticas multilaterais de preservação do planeta.

A contrariedade ao Acordo de Paris manifestada pelo atual presidente norte-americano e suas convicções sobre o clima eram conhecidas desde o período eleitoral de 2016, inclusive, a retirada das negociações e o abandono de medidas em concordância com o Acordo de Paris faziam parte de suas plataformas de governo se caso eleito. O que era, portanto, algo certo entre os norte-americanos, atualmente abala as estruturas da urgente redução de gases de efeito estufa na atmosfera que causas severas alterações climáticas, entre elas, o aquecimento global.

Os discursos contrários as demandas e as iniciativas ambientais que envolvem a diminuição das mudanças climáticas tomaram corpo com o anúncio de uma nova política energética americana, bem como um modelo de política estratégica em relação ao clima que prevê a assinatura da Ordem Executiva de Independência Energética pelo chefe de Estado norte-americano. E tudo isso, ocorreu de fato em junho de 2017.

Os atos de Washington não consideraram que empresas norte-americanas já investiram muitos bilhões de dólares em energia renovável dentro e fora do país. Além disso, esse mercado é promissor para os Estados Unidos, ainda que a liderança esteja em disputa com China, Alemanha e Japão, entre outros. O que o mundo e os Estados Unidos precisam neste momento é de uma visão limítrofe e atrasada. A nova política climática norte-americana pode retardar o avanço para uma economia de baixa emissão de dióxido de carbono $\left(\mathrm{CO}_{2}\right)$, mas, espera-se, não poderá sozinho alterar os rumos da economia mundial, inclinada nesse sentido. Com referência ao Acordo de Paris, os Estados Unidos o ratificaram em setembro de 2016. Este é 


\section{O ACORDO DE PARIS NA PERSPECTIVA DA INDEPENDÊNCIA ENERGÉTICA DE WASHINGTON}

um procedimento discricionário, e os governos decidiram concordar com as determinações estabelecidas no documento e se comprometeram a respeitar e cumprir fielmente suas obrigações. Uma vez ratificado o Acordo de Paris torna-se irretratável. Cabe agora aos Estados Unidos somente a denúncia do Acordo. O próprio Acordo de Paris estabeleceu os critérios para a denúncia do documento. E o governo norte-americano só poderá denunciar o Acordo após três anos da entrada em vigor do mesmo, o que se deu em 04 de novembro de 2016. Considerando que o texto do Acordo menciona que os efeitos da denúncia irão ocorrer somente após um ano do recebimento dela, os Estados Unidos só estarão efetivamente desobrigados em novembro de 2020.

Na prática, os impactos são ínfimos, uma vez que o Acordo de Paris já não estabelecia a obrigatoriedade de cumprimento de suas metas por parte de cada um dos países. Apesar das nações terem estabelecido metas audaciosas, as ações são voluntárias nos termos do documento.

O maior impacto deve ser sentido na contribuição financeira, uma vez que os Estados Unidos deveriam dar para auxiliar os demais países para que pudessem cumprir as metas do Acordo de Paris. Contudo, diante do novo posicionamento americano, China, Japão, Índia e União Europeia estão se aproximando cada vez mais e já manifestaram o seu apoio à continuidade do Acordo de Paris e adiantaram que empregarão seus esforços para que realmente ocorra a efetiva prática de ações que minimizem as mudanças climáticas e que apoiem os países em desenvolvimento neste novo cenário, em prol da redução das mudanças climáticas.

Diante disso, na contramão global, a decisão do governo norte-americano jogou uma cortina de fumaça sobre as questões climática, mas não consegue cimentar o caminho que já fora construído em prol da preservação do meio ambiente, da promoção de inciativas de combate ao aquecimento global. No máximo, o império americano se retrai e ruma a passos largos para o isolacionismo na ordem mundial. Talvez esse venha a ser o maior efeito da Ordem Executiva de Independência Energética de Washington. 


\section{REFERÊNCIAS}

ALLISSON, N. L. et al. TCD. The Copenhagen Diagnosis, 2009: Updating the world on the Latest Climate Science. The University of New South Wales Climate Change Research Centr:, Sydney, 2009.

ALVES, José Eustáquio Diniz. Concentração de CO2 na atmosfera chega a 410 ppm. in EcoDebate. 24 de abril de 2017. Disponível em: https://www.ecodebate.com.br/2017/04/24/concentracao-de-co2-na-atmosfera-chega-410ppm-artigo-de-jose-eustaquio-diniz-alves/. Acesso em 03 de março de 2018.

BATISTA, Henrique Gomes. Donald Trump retira EUA do Acordo de Paris sobre o clima. O Globo. 01 de junho de 2017. Disponível em: https://oglobo.globo.com/sociedade/sustentabilidade/donald-trump-retira-eua-do-acordo-deparis-sobre-clima-21423570. Acesso em 03 de março de 2018.

BRASIL, Ministério da Ciência e Tecnologia. Efeito Estufa e a Convenção sobre Mudança do Clima, Cartilha. Brasília: 1999.

CHURCH, John. A; WHITE, Neil J. A 20th century acceleration in global sea level rise, Geophysical Research Letters, Vol. 33, Issue 1, 2006.

DEKSEN, Chris. BROWN, Ross. Spring snow cover extent reductions in the 2008-2012 period exceeding climate model projections. Geophysical Research Letters. olume 39, Issue 19, 16 October, 2012.

DERANI, Cristiane. Direito Ambiental Econômico. 3. ed. São Paulo: Saraiva, 2008.

DIÁRIO DE NOTÍCIAS. Clima: Mundo reage à saída dos EUA do Acordo de Paris e lamenta decisão de Trump. 01 de junho de 2017. Disponível em: http://www.dn.pt/lusa/interior/clima-mundo-reage-a-saida-dos-eua-do-acordo-de-paris-elamenta-decisao-de-trump-8527256.html. Acesso em 03 de março de 2018.

DINH, Nguyen Quoc. DAILLIER, Patrick. PELLET, Alain. Direito internacional Público. Lisboa: Fundação Calouste Gulbenkian, 1999.

FLECK, Isabel. Folha de São Paulo. Trump assina decreto que desfaz política ambiental de Obama. 28 de março de 2017. Disponível em: http://www1.folha.uol.com.br/mundo/2017/03/1870482-trump-assina-decreto-que-revisapolitica-ambiental-de-obama.shtml. Acesso em 03 de março de 2018.

FONSECA, F. Eduardo. A Convergência entre a Proteção Ambiental e a Proteção da Pessoa Humana no Âmbito do Direito Internacional. Revista Brasileira de Política Internacional (Impresso), v. 50, p. 121-138, 2007 


\section{O ACORDO DE PARIS NA PERSPECTIVA DA INDEPENDÊNCIA ENERGÉTICA DE WASHINGTON}

FOUCAULT. Alain. O Clima: história e devir do meio ambiente terrestre. Lisboa: Instituto Piaget, 2015.

G1. Natureza. EUA se juntarão a Síria e Nicarágua no 'clube' dos países fora do Acordo de Paris. 01 de junho de 2017. Disponível em: http:/g1.globo.com/natureza/noticia/eua-sejuntarao-a-siria-e-nicaragua-no-clube-dos-paises-fora-do-acordo-de-paris.ghtml. Acesso em 03 de março de 2018.

GIRARDI, Giovana. O Estado de São Paulo. IHU. Instituto Humanitas. Ato de Trump praticamente tira os EUA do Acordo de Paris. 28 de março de 2017. Disponível em: http://www.ihu.unisinos.br/566252-ato-de-trump-praticamente-tira-os-eua-do-acordo-deparis. Acesso em 03 de março de 2018.

GRATH, Matt. Cinco efeitos globais da saída dos EUA do Acordo de Paris. BBC Brasil. 1 de junho de 2017. Disponível em: http://www.bbc.com/portuguese/internacional-40114352. Acesso em 03 de março de 2018.

HAWKINS, Ed. Spiralling global temperatures from 1850-2017. Climate Lab Book. Open climate Science. 2017. Disponível em: http://www.climate-lab-ook.ac.uk/spirals/. Acesso em 03 de março de 2018.

IPCC. Intergovernmental Panel on Climate Change. Synthesis Report: Summary for Policymakers. Climate Change, 2014. Disponível em: http://www.ipcc.ch/pdf/assessmentreport/ar5/syr/AR5_SYR_FINAL_SPM.pdf. Acesso em 03 de março de 2018.

IS. Instituto Socioambiental. Widgets Socioambientais: COPs. Disponível em: https://widgets.socioambiental.org/widgets/timeline/535\#20. Acesso em 03 de março de 2018.

KAWOK, R.; ROTHROCK, D. A. Decline in Arctic sea ice thickness from submarine and ICESAT records: 1958-2008. Geophysical Research Letters, vol. 36, issue 15, 2009.

KEOHANE, R.; VICTOR, D. The regime complex for climate change. The Harvard Project on International Climate Agreements. Discussion Paper. 10-33. January, 2010.

LEOPOLDO, Ricardo. O Estado de São Paulo. IHU. Instituto Humanitas. Desregulamentação ambiental de Trump ameaça acordo de Paris, diz especialista. 29 de março de 2017. Disponível em: http://www.ihu.unisinos.br/566253-desregulamentacao-ambiental-de-trumpameaca-acordo-de-paris-diz-especialista. Acesso em 03 de março de 2018.

LEVITUS, S., et al. Global ocean heat content 1955-2008 in light of recently revealed instrumentation problems Geophysical Research Letters, VOL. 36, L07608, 2009.

NASA. National Aeronautics and Space Administration. Earth Observatory. Snow Cover \& Land Surface Temperature. 2017. Disponível em: https://earthobservatory.nasa.gov/GlobalMaps/view.php?d1=MOD10C1_M_SNOW\&d2=MO D11C1_M_LSTDA. Acesso em 03 de março de 2018. 
. National Aeronautics and Space Administration. Goddard Space Flight Center.

Sciences and Exploration Directorate. Earth Sciences Division. 2016. Disponível em: https://www.giss.nasa.gov/research/news/20170118/. Acesso em 03 de março de 2018.

NASCIMENTO E SILVA, Geraldo Aulálio do. Direito ambiental internacional: meio ambiente, desenvolvimento sustentável e os desafios da nova ordem mundial. Rio de Janeiro: Thex Editora, 1995.

NASEM. National Academies of Sciences, Engineering, and Medicine. 2016. Attribution of Extreme Weather Events in the Context of Climate Change. Washington, DC: The National Academies Press. 2016.

NOAA. National Oceanic and Atmospheric Administration. Global Climate Report: Annual 2016. Disponível em: https://www.ncdc.noaa.gov/sotc/global/201613. Acesso em 03 de março de 2018.

$\begin{array}{llll} & \text { National Oceanic and Atmospheric Administration. PMEL. Carbon Group. } \\ \text { What is Ocean } & \text { Acidification?. }\end{array}$ https://www.pmel.noaa.gov/co2/story/What+is+Ocean+Acidification\%3F. Acesso em 03 de março de 2018.

National Oceanic and Atmospheric Administration. Trends in Atmospheric

Carbon Dioxide. 2017. Disponível em:

https://www.esrl.noaa.gov/gmd/ccgg/trends/graph.html. Acesso em 03 de março de 2018.

NSIDC. National Snow \& Ice Data Center. In the criosphere sending singnals about climate change. State of the Cryosphere reviews in Science, 14 april. 2017. Disponível em: http://nsidc.org/cryosphere/sotc/glacier_balance.html. Acesso em 03 de março de 2018.

O POVO. Acordo de Paris: Mark Zuckerberg, outras organizações e políticos americanos reagem à saída dos EUA. 2 de junho de 2017. Disponível em: http://www.opovo.com.br/noticias/mundo/2017/06/acordo-de-paris-mark-zuckemberg-outrasorganizacoes-e-politicos-amer.html. Acesso em 03 de março de 2018.

ONU. Organizações das Nações Unidas. Saída dos EUA de acordo do clima é 'grande decepção’, diz secretário-geral da ONU. Stéphane Dujarric, porta-voz do secretário-geral da ONU, António Guterres, 1 de junho de 2017. Disponível em: https://nacoesunidas.org/saidados-eua-de-acordo-do-clima-e-grande-decepcao-diz-secretario-geral-da-onu/. Acesso em 03 de março de 2018.

PEREDA, Cristina. El País. IHU. Instituto Humanitas. Trump desmantela política ambiental de Obama contra a mudança climática. 29 de março de 2017. Disponível em: http://www.ihu.unisinos.br/566239-trump-desmantela-politica-ambiental-de-obama-contra-amudanca-climatica. Acesso em 03 de março de 2018.

POLYAK, L. et.al., History of Sea Ice in the Arctic, in Past Climate Variability and Change in the Arctic and at High Latitudes, U.S. Geological Survey, Climate Change Science Program Synthesis and Assessment Product 1.2, January 2009. 
SABINE, C. L. et.al. "The Oceanic Sink for Anthropogenic CO2,” Science vol. 305, 16 july, 2004. p. 367-371

SILVA, Robson Willians da Costa; PAULA, Beatriz Lima. Causa do aquecimento global: antropogênica versus natural. Terræ Didatica, 5(1):42-49, 2009. Disponível em: http:// www.ige.unicamp.br/terraedidatica/. Acesso em 03 de março de 2018.

SOARES, Guido Fernando e Silva. A proteção internacional do meio ambiente. Barueri: Manole, 2003.

- Direito internacional do meio ambiente: emergência, obrigações e responsabilidades. São Paulo: Atlas, 2003.

TREVISAN, Claudia; CHADE, Jamil. Trump tira EUA de acordo climático e quer renegociação; UE e China rejeitam. O Estadão. Internacional. 01 de junho de 2017. Disponível em: http://internacional.estadao.com.br/noticias/geral,trump-vai-retirar-os-estadosunidos-de-acordo-do-clima-de-paris,70001822261. Acesso em 03 de março de 2018.

UNFCC. United Nations Framework Convention on Climate Change Convenção. 21 ${ }^{\circ}$ Conference of the Parties. Acordo de Paris, 2015. Disponível em: https://nacoesunidas.org/cop21/. Acesso em 03 de março de 2018.

UNFCC. United Nations Framework Convention on Climate Change, 2017. Disponível em: https://nacoesunidas.org/cop21/. Acesso em 03 de março de 2018.

VARELLA, Marcelo D. Direito internacional econômico ambiental. Belo Horizonte: Del Rey, 2004.

VEIGA, José Eli da. A emergência socioambiental. São Paulo: Editora Senac, 2007. 